\title{
Potter's syndrome: a case report
}

\section{Latika*, Smiti Nanda, Savita Singhal, Amandeep Chahal}

Department of Obstetrics and Gynecology, PT. B. D. Sharma, PGIMS, Rohtak, Haryana, India

Received: 20 January 2019

Accepted: 05 March 2019

\section{*Correspondence:}

Dr. Latika,

E-mail: latika.duhan@gmail.com

Copyright: (c) the author(s), publisher and licensee Medip Academy. This is an open-access article distributed under the terms of the Creative Commons Attribution Non-Commercial License, which permits unrestricted non-commercial use, distribution, and reproduction in any medium, provided the original work is properly cited.

\begin{abstract}
Potter's syndrome is a rare congenital disorder characterized by characteristic atypical appearance of a newborn due to the oligohydroamnios experienced during the intrauterine life. Its incidence varies from 1 in 2000 to 1 in 5000.40 years old G7P4L1 A2 at 37 weeks of period of gestation was admitted at a tertiary care institute with labour pains. Her previous obstetric history included three full term vaginal deliveries, two of the babies expired in postnatal period of 2 months and 7 days age respectively. One was alive and healthy. In fourth pregnancy she underwent emergency LSCS, but baby expired 5 months after birth. She had history of 2 abortions which were spontaneous and not followed by curettage. She also gave history of intake of some drugs at 6th week of gestation prescribed by a local Baba to have a male child. Her ultrasonography revealed fetus with bilateral renal agenesis. On per abdomen examination, clinically liquor was very much reduced, Fetal heart sounds were not heard. She delivered vaginally a still born fetus with ambiguous genitalia, anal atresia and malformed limbs. The fetus had typical facial appearance of "potter facies". Potter's Syndrome or Sequence is a rare fatal disorder. Apart from typical Potter's facies, pulmonary hypoplasia, skeletal deformities are associated with this condition, severity depends on the degree and duration of oligohydramnios. Therefore, it is very important to pick up this condition during antenatal ultrasound at earlier gestation so that timely decision regarding further workup and pregnancy termination can be undertaken. This case report emphasizes upon the importance of regular antenatal check ups and examination in each and every patient as it picks up the suspicious cases which can lead to further workup, definite diagnosis of the condition and timely decision regarding management.
\end{abstract}

Keywords: Congenital disorder, Potter facies, Potter's syndrome, Rare

\section{INTRODUCTION}

Potter's syndrome is a rare congenital disorder characterized by characteristic atypical appearance of a newborn due to the oligohydroamnios experienced during the intrauterine life.

This condition was first described by pathologist Edith Potter in $1946 .{ }^{1}$ Its incidence varies from 1 in 2000 to 1 in $5000 .^{2}$
Male predilection is seen due to increased incidence of Prune Belly Syndrome and obstructive uropathy due to Posterior urethral valve in them. ${ }^{3}$

It is accompanied by oligohydramnios which may have different etiologies: Bilateral renal agenesis, obstructive uropathy, renal hypoplasia, polycystic or multi-cystic kidney disease, premature rupture of membranes which results into characteristic physical deformities and lung hypoplasia. ${ }^{4,5}$ 
Main cause of increased morbidity and poor prognosis of fetus is lung hypoplasia. There are increased chances of recurrence in future pregnancies $(3-6 \%){ }^{6}$

\section{CASE REPORT}

Here authors describe a case report of patient, 40 years old G7P4L1 A2 at 37 weeks of period of gestation who was admitted at a tertiary care institute with labour pains. Her husband was also 40 years old. On enquiring, it was found that she was married for 23 years. Her obstetric history was as follows:

\section{Para 1}

Female baby born by full term vaginal delivery 21 years back, expired at 2 months of age, reason not known to parents except that the baby developed some swelling over legs before death.

\section{Para 2}

Female baby born by full term vaginal delivery 17 years back. Baby expired 7 days after birth.

\section{Para 3}

Female baby born by full term vaginal delivery 14 years back. Baby alive and healthy.

\section{Para 4}

Female baby born by emergency cesarean section 11 years back. Baby expired 5 months after birth. Fever of 45 days duration of unknown etiology was the most probable reason according to parents.

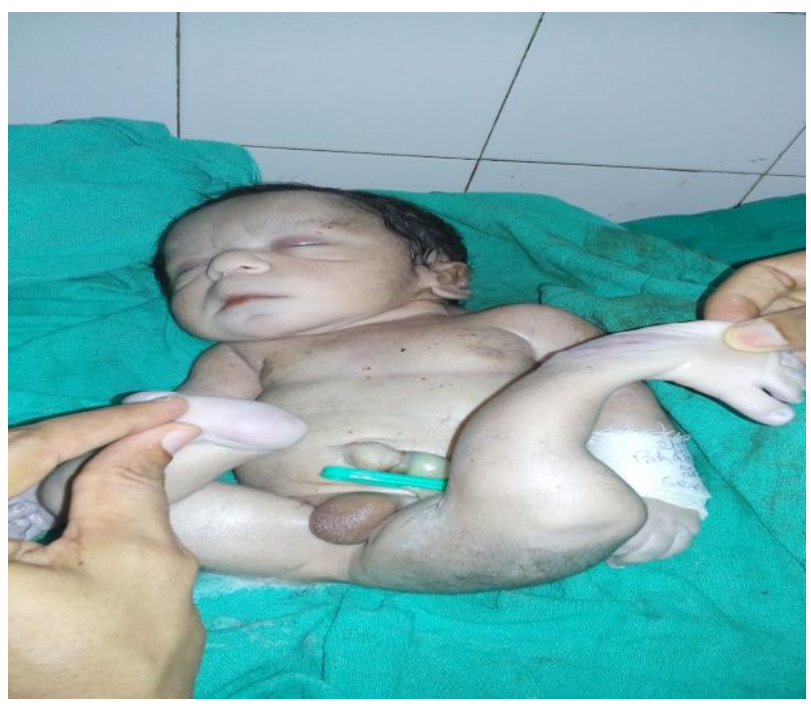

Figure 1: Anal atresia in Potter's syndrome.

She had history of 2 abortions which were spontaneous and not followed by curettage. She also gave history of intake of some drugs at $6^{\text {th }}$ week of gestation prescribed by a local Baba to have a male child. Her ultrasonography revealed that fetus was having bilateral renal agenesis. On per abdomen examination, clinically liquor was very much reduced, Fetal heart sounds were not heard. She delivered vaginally a still born fetus with ambiguous genitalia, anal atresia and malformed limbs. The fetus had typical facial appearance of "potter facies" which consists of a flat nose, recessed chin, epicanthal folds and low set abnormal ears.

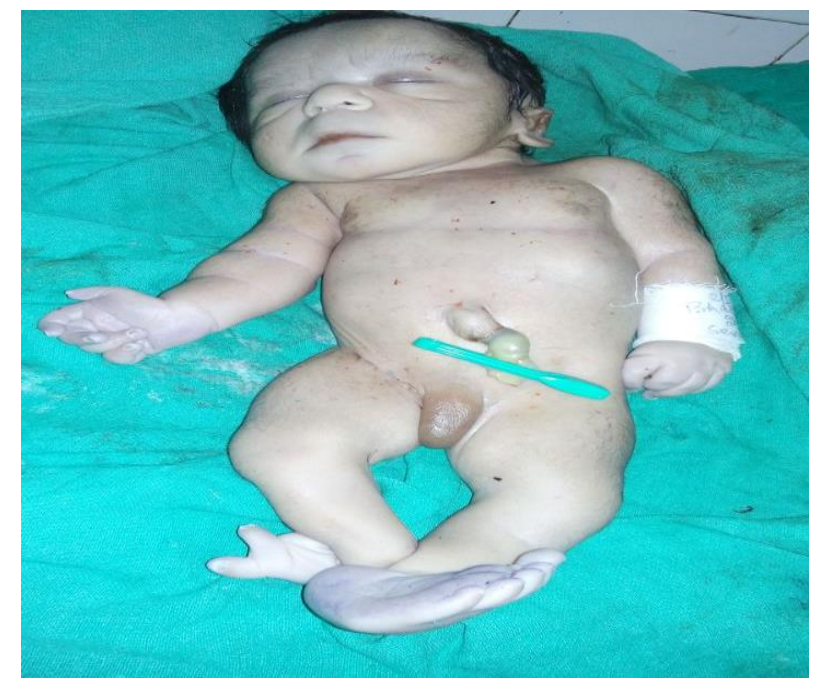

Figure 2: Malformed limbs in Potter's syndrome.

\section{DISCUSSION}

Potter's Syndrome or Sequence is a rare fatal disorder. Some authors believe that Potter's sequence rather than Potter's Syndrome is a better term to describe this entity because there are different etiologies which lead to the common result of oligohydramnios, which in turn leads to characteristic physical appearance and lung hypoplasia and sequelae. Potter's facies is described as flat nose, recessed chin, prominent epicanthal folds and low set abnormal ears. Degree of pulmonary hypoplasia in such cases depends on the severity and duration of oligohydramnios. Also important is the stage of lungs development at which oligohydramnios occurred. Skeletal anomalies frequently associated with this condition are hemivertebra, sacral agenesis.

Oligohydramnios is defined as decreased in liquor amni for the period of gestation. In intrauterine life, prior to 16 weeks of gestation, proportion of liquor amnii production depends on transmembrane flow, after that it is mainly by fetal urine production. Its exact genetic basis is still not known, studies are going on. Evidence has been found regarding role of transcription factors Lim1 and Pax 2 during nephrogenesis and deficiency leading to renal agenesis in mice. ${ }^{7,8}$ Potter's Syndrome can be divided into four subgroups depending on the underlying etiology. ${ }^{9}$ Classic Potter's Syndrome is always fatal. ${ }^{3}$ Therefore, it is very important to pick up this condition during antenatal 
ultrasound at earlier gestation so that timely pregnancy termination can be done. Workup of patients with Potter's Syndrome includes search for other nonrenal defects, autopsy, chromosomal analysis, urologic examination or renal ultrasound of parents. Ultrasonographic prenatal monitoring of further pregnancies should be done in such cases because of chances of recurrence in such families. In present case age factor of parents, history of early neonatal deaths, history of intake of some medications affecting chromosomal division in first trimester leads to possibility of some genetic causes for bilateral renal agenesis leading to oligohydroamnios leading to potter sequence.

\section{CONCLUSION}

This case report emphasizes upon the importance of regular antenatal check ups and examination in each and every patient as it picks up the suspicious cases which can lead to further workup and definite diagnosis of the condition and timely decision regarding management.

Funding: No funding sources Conflict of interest: None declared

Ethical approval: Not required

\section{REFERENCES}

1. Edith L. Potter. Facial characteristics of infants with bilateral renal agenesis. Am J Obstet Gynecol. 1946;51:885-8.
2. Information about Potter's syndrome. Available at: www.potterssyndrome.org/potterslinks.html

3. Jason C. University of Michigan, Department of Pediatric. Division of Nephrology. Available at: http://www.potterssyndrome.org/definition.html

4. Fantel AG, Shepard TH. Potter syndrome. Nonrenal features induced by oligoamnios. Am J Dis Child. 1975;129(11):1346-7.

5. Vanderheyden T, Kumar S, Fisk NM. Fetal renal impairment. Semin Neonatol. 2003;8(4):279-89.

6. Curry CJ, Jensen K, Holland J, Miller L, Hall BD. The Potter sequence: A clinical analysis of 80 cases. Am J Med Genet. 1984;19:679-702.

7. Paces-Fessy M, Fabre M, Lesaulnier C, Cereghini S. Hnf1b and Pax2 cooperate to control different pathways in kidney and ureter morphogenesis. Hum Mol Genet. 2012;21(14):3143-55.

8. Guertl B, Senanayake U, Nusshold E, Leuschner I, Mannweiler S, Ebner B, et al. Lim1, an embryonal transcription factor, is absent in multicystic renal dysplasia, but reactivated in nephroblastomas. Pathobiol. 2011;78(4):210-9.

9. Ikeda Y, Lister J, Bouton JM, Buyukpamukcu M. Congenital neuroblastoma, neuroblastoma in situ, and the normal fetal development of the adrenal. J Pediatr Surg. 1981;16:636-44.

Cite this article as: Latika, Nanda S, Singhal S, Chahal A. Potter's syndrome: a case report. Int J Reprod Contracept Obstet Gynecol 2019;8:1683-5. 